
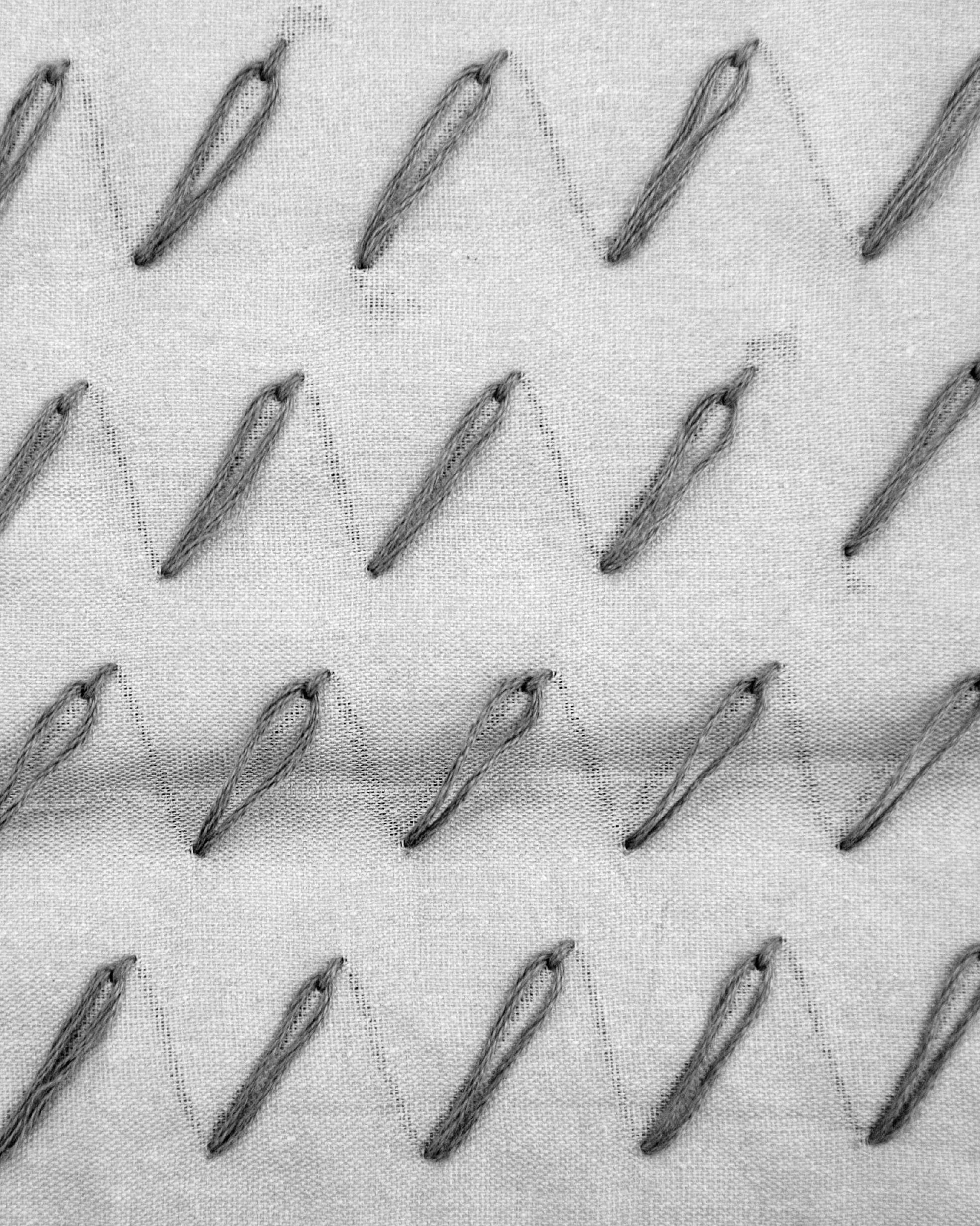


\section{MÁS ALLÁ DE ISLA DE PASCUA: MIGRACIÓN E IDENTIDAD EN LA} SOCIEDAD RAPANUI CONTEMPORÁNEA'

\section{Beyond Easter Island: Migration and identity in contemporary rapanui society}

\section{DIEGO MUÑOZ AZÓCAR*}

Fecha de recepción: 20 de junio de 2014 - Fecha de aprobación: 26 de septiembre de 2014

\section{Resumen}

La sociedad rapanui actual se compone de comunidades territorialmente dispersas. Mediante diferentes formas de articulación, configuran una noción de totalidad social centrada en Isla de Pascua como lugar identitario de arraigo. En este artículo propongo que esta totalidad social se articula mediante a una red de conexiones que vincula la Isla de Pascua (Rapa Nui) a Chile continental y a Polinesia francesa. Rapa Nui produce un espacio de alteridad en el cual los isleños residentes en la isla construyen una identidad cultural. Queremos mostrar que los desplazamientos y la residencia permanente de personas rapanui fuera de Isla de Pascua no representan ni generan sentimientos de ruptura con la comunidad de origen, por el contrario, mantienen una serie de obligaciones sociales que ayudan a configurar una noción de totalidad bajo la forma de una comunidad translocal.

Palabras Clave: Rapa Nui, comunidad translocal, migración, identidad, alteridad.

\section{Abstract}

Current Rapanui society is composed of scattered territorial communities. Through various means, these form a social totality or identity centered on Easter Island as the place of origin. In this paper, I propose that this social totality is articulated by a network of connections between Easter Island, mainland Chile and French Polynesia. Rapanui provides a space of alterity in which the islanders resident on the island construct a cultural identity. I intend to show that the movements and permanent residence of the Rapanui peoples, outside of Rapa Nui do not represent or generate feelings of rupture with the community of origin. On the contrary, a series of social obligations are maintained that help form the social totality from the translocal community.

Key words: Rapa Nui, translocal community, migration, alterity, cultural identity.

* Antropólogo. Doctorante Ecole de Hautes Etudes en Sciences Sociales. Centre de Recherche et de Documentation sur l'Oceanie (UMR 7308) Correo electrónico: diego.munoz@ehess.fr 


\section{Introducción: La lejana Rapa Nui.}

La sociedad rapanui ${ }^{2}$ representa una historia compleja de transformaciones socioculturales, no solamente en lo que respecta a su pasado más lejano, sino también a su historia reciente. La sociedad insular pasó de ser una comunidad extremadamente aislada con un régimen económico, marcial y eclesiástico (1900-1965) que impedía a los isleños salir de Rapa Nui, a una sociedad radicalmente abierta desde mediados de los años 60 (Cristino, Recasens, Vargas, González \& Edward,1984; Cristino \& Fuentes 2011) momento en que Isla de Pascua es formalmente incorporada al Estado chileno (Porteous, 1981; McCall, 1996; Seelenfreund, Grifferos, Hucke \& Ramirez, 2004; Delsing, 2009) y en que la actividad turística comienza a acaparar la economía local (cf. Cristino et al.1984; Porteous, 1981; Di Castri 1999).

Según el censo chileno de 2002, la población total de Isla de Pascua ascendía a 3.791 personas, de las cuales el 60\% (2.269 personas) se declaró perteneciente a la etnia rapanui; mientras que la población no-rapanui se calculaba en un 40\% (1.522 personas entre chilenos continentales ${ }^{3}$ y extranjeros). Según las estimaciones del Instituto Nacional de Estadísticas (INE), para el año 2012 la población ascendería a 5.167 habitantes (BNC, 2013) ${ }^{4}$.

En nuestras experiencias de terreno en Rapa Nui (en los años 2009, 2011 y 2014) hemos podido constatar la creciente preocupación ante lo que los rapanui llaman "migración" es decir, el arribo masivo de chilenos continentales. Rapa Nui comienza a ser una tierra de migración, como muchas otras islas del Pacifico (Toullelan \& Gille, 1999).
La diferencia radica en que a pesar de su talla reducida (163 kilómetros cuadrados y un sólo poblado), actualmente es una tierra de acogida de inmigrantes más que una de éxodo.

Al interesarnos en las experiencias migratorias de los insulares, hemos podido identificar que la sociedad rapanui de los últimos cincuenta años ha conocido dos fases migratorias. La primera comienza cuando las prohibiciones a la libre circulación impuesta por la administración chilena $^{5}$ dejan de tener efecto (de 1966 en adelante), y que se caracterizó por el hecho que muchos isleños comenzaron a instalarse en Chile continental (en las ciudades de Valparaíso, Quilpué y Santiago, principalmente) y a viajar a Tahiti (Polinesia Francesa). En este período Rapa Nui devino una tierra de éxodo. La segunda y actual fase se caracteriza por la articulación de Rapa Nui a una red de circulación de personas, producida principalmente por el flujo turístico, pero también el retorno de muchos rapanui que habían vivido fuera de la isla, y al arribo de chilenos continentales seducidos por las posibilidades salariales que la actividad turística promete. Rapa Nui comienza a ser una tierra de acogida.

En este artículo analizaremos la actual sociedad rapanui en sus conexiones hacia Chile continental y Polinesia francesa, desmontando la antigua noción que plantea a Rapa Nui como un lugar aislado. Proponemos que la sociedad rapanui se compone de comunidades territorialmente dispersas que, mediante diferentes mecanismos de articulación, configura una noción de totalidad social centrada en Isla de Pascua como lugar identitario de arraigo. Nos resulta imposible comprender la sociedad insular sin analizar las maneras en que ésta se articula con Chile 
continental y la Polinesia francesa, sin contemplar el rol que juega la migración de personas rapanui, la instalación de éstas fuera de la isla y las relaciones que establecen entre el lugar de habitación y el lugar de origen, como también los efectos del arribo de personas del continente ${ }^{6}$ y el rol del turismo. Es sintomático que en los últimos diez años, según las estimaciones del Instituto Nacional de Estadísticas (INE), la población en la isla haya aumentado en un $36,30 \%$, siendo que la variación a nivel país es de un 15,10\% (BNC, 2013). Nos parece igualmente relevante que nuestro propio análisis de las cifras del censo chileno de 2002, arrojó que un $51 \%$ de la población rapanui habitaba en Chile continental y que de éste, el $26 \%$ se concentraba en la ciudad de Santiago (Muñoz, 2007). De la misma manera, resulta revelador que después de los años 70 los desplazamientos hacia Polinesia Francesa sean cada vez más frecuentes.

El grueso de la información que aquí se analiza es el resultado de nuestras investigaciones etnográficas realizadas durante los últimos siete años en Santiago de Chile, Rapa Nui y Tahiti, en el marco de nuestra investigación de tesis doctoral. En nuestra investigación, hemos utilizado las estrategias de "mapeo" sugeridas por George Marcus (2001) para hacer del método etnográfico, una herramienta de análisis de procesos globales ${ }^{7}$.

El artículo se organiza en siete secciones, la primera trata de las experiencias migratorias rapanui hacia Chile continental y Polinesia francesa así como los efectos que ha tenido la instalación de chilenos continentales en Rapa Nui. Luego analizaremos las maneras en que los inmigrantes se mantienen vinculados a la comunidad de origen, dando cuenta de diferentes mecanismos de articulación entre los "enclaves rapanui en el extranjero" y la sociedad insular. En un tercer momento plantearemos que el circuito migratorio crea y hace circular una serie de representaciones sobre el exterior activando procesos de "cerradura" de la sociedad insular. Concluiremos este artículo proponiendo que la sociedad rapanui ha estructurado una comunidad que trasciende los límites geográficos de Isla de Pascua.

\section{La familia rapanui dispersa: Santiago y Tahiti como enclaves rapanui en el exterior.}

A lo largo de nuestro trabajo etnográfico hemos registrado una serie de biografías de movilidad (Marcus, 2001), con las que hemos podido determinar que las experiencias de desplazamiento de los rapanui dan cuanta de un proceso de migración circular (Sahlins, 2007). Este tipo de migración consiste de tres momentos consecutivos. En primer lugar, se trata de las experiencias de salida de Rapa Nui, seguidas por las de instalación en el lugar de llegada y finalmente las de retornar a Isla de Pascua. Estas experiencias nos han permitido comprender las condiciones sociales y las motivaciones que gatillaron la salida de Rapa Nui, las estructuras sociales que actúan en la integración del migrante en la sociedad de acogida, en las experiencias del retorno, y comprender los procesos de reintegración en la sociedad insular. Al estudiar estas experiencias hemos identificado que los rapanui mantienen vínculos de diferente naturaleza y en diferentes grados de compromiso con la comunidad de origen, haciéndose parte estructurante de una comunidad translocal. 
Las biografías migratorias nos han mostrado también la importancia de las relaciones de parentesco en la migración rapanui. En primer lugar, constatamos que la actual familia rapanui ha asumido un patrón de residencia neolocal extremo, donde sus miembros se encuentran dispersos en diferentes y alejados lugares de residencia, pero manteniendo diferentes vínculos sociales entre ellos. En segundo lugar, identificamos que aquellos que se desplazan lo hacen siempre dentro de un círculo de conocidos ya asentados en los lugares de arribo. De cierta manera, recibir parientes es una nueva obligación social de la familia rapanui dispersa. La migración rapanui ha construido un espacio social más amplio y un universo de obligaciones a cumplir entre migrantes y radicados, que desbordó el espacio finito de Isla de Pascua.

Las biografías recopiladas nos han permitido comprender que la migración regular hacia Chile continental y Polinesia francesa, se inicia casi de manera simultánea hacia finales de los años 60 y se vuelve frecuente hacia los 80 . Sin embargo, sabemos que existieron intentos en los años anteriores en ambas direcciones, explicados por las condiciones de aislamiento impuestas por la administración chilena (Englert, 1960; Peteuil, 2004). A continuación, explicaremos cómo se han formado enclaves rapanui en el exterior y cómo se estructuran por factores históricos y contextuales diferentes.

\subsection{Irse al continente: Santiago como enclave.}

Antes que los rapanui adquiriesen sus derechos ciudadanos en los años 60 , sólo tenían tres maneras de viajar a Chile continental:
1) enrolándose en las Fuerzas Armadas, ya fuese en la Marina (que hasta 1965 era la representante del Estado) o en Carabineros ${ }^{8}$; 2) en el marco de un programa de ayuda de la Sociedad de Amigos de Isla de Pascua (un grupo de personeros de la alta intelectualidad chilena de los años 4050) que incentivó y acogió a jóvenes isleños para que continuaran estudios en Santiago; 3) intentando escapar escondidos en las bodegas de los barcos de la Armada o de la Compañía Explotadora de Isla de Pascua ${ }^{9}$ que llegaban a Rapa Nui (Muñoz, 2007; Foerster, Ramírez \& Zurob, 2012).

Estos primeros migrantes rapanui en Chile continental, formaran en los años 60 el llamado "Comité de Adelanto Pascuense"10, organización que jugará un importante rol en las negociaciones con el Estado para dar término al régimen marcial que existía en Rapa Nui (Goñi, 1983; Foerster et al. 2012). En este periodo se formarán también los primeros profesores normalistas isleños que volverán a Rapa Nui y ejercerán cargos de autoridad en diferentes dominios. Alfonso Rapu, líder del movimiento por los derechos ciudadanos en Rapa Nui, fue parte del grupo de profesores retornados (Grifferos, 1995).

Será luego de los cambios políticos y económicos vividos en Isla de Pascua de los años 60 (cf. Grifferos, 1995; Seelenfreund et al. 2004; Foerster et al., 2012) que los rapanui saldrán libremente y comenzarán a asentarse en Valparaíso y las comunas vecinas como Quilpué o Villa Alemana. Hoy los isleños recuerdan a las familias Atan, Haoa y Rapahango como aquellas de Quilpué y a los Pakomio, Pakarati y Rapu como los de Valparaíso. La instalación en Santiago es posterior a aquella de la región del puerto, pero es y fue, la más permanente. 
Adriana Goñi (1983), quien pudo trabajar con la generación de estos primeros migrantes, estimó que entre 1969 y 1971, había 400 rapanui viviendo en Chile continental. La principal razón que Goñi identifica para esta migración, fue la creciente expectativa de los isleños por alcanzar un bienestar material similar al de los continentales que llegaron a ocupar los cargos públicos; similar al que tenían los militares de la base norteamericana ${ }^{11} \mathrm{o}$ al de los turistas. Goñi explica: "existe una gran cantidad de pascuenses que dice "venir a conocer la patria..." o "a ver este lugar de donde van todas las cosas nuevas a Pascua..." (Goñi, 1983: 243).

Las instalaciones en Chile continental iniciadas con posterioridad a los años 60 , y que nosotros pudimos estudiar gracias a nuestro contacto con migrantes rapanui de segunda y tercera generación (los hijos y nietos de la migrantes con los que trabajó Goñi), respondieron a otro patrón. Corresponden a un proceso familiar que se vio incrementado con la práctica de dar preferencia a matrimonios entre rapanui y continental por sobre a los de rapanui con rapanui.

Los isleños que hoy tienen entre 40 y 60 años nos explicaron que sus padres impusieron juventud, un fuerte tabú del incesto, lo que impedía que pudiesen casarse con otros isleños. Esto significó que debieron buscar pareja entre los extranjeros llegados a la isla, que en su mayoría eran chilenos continentales. Irse de la isla se transformó en una obligación. Uno de los correlatos directos de esto, fue que la nueva familia se asentó en el lugar de origen del cónyuge, en especial que mujeres rapanui casadas con chilenos continentales se fueran a vivir fuera de la isla (McCall, 1998; Muñoz, 2014a).
Contrariamente a la experiencia de sus padres, los jóvenes rapanui de hoy (o la tercera generación de migrantes) invocan como motivo para dejar la isla, la búsqueda de nuevas oportunidades en educación. Entre ellos, la idea de irse de Rapa Nui parece ser una experiencia normal, aunque no necesaria, como en el caso de sus padres. Muchos son los jóvenes que año a año parten a vivir al continente, pero pocos son los que efectivamente, terminan sus estudios. Las nuevas condiciones económicas de Rapa Nui desmotivan la continuación de estudios superiores o de profesionalización. Hoy muchos jóvenes y adultos son dueños de hostales o cabañas que arriendan a alto precio a los afuerinos.

Para los rapanui ancianos, la migración tiene que ver con razones médicas, dada la falta de especialistas en el hospital local. Si bien el año 2011 se inauguró un nuevo y moderno hospital en Isla de Pascua, muchos enfermos crónicos deben pasar algunos meses en Santiago o Valparaíso. Hace al menos siete años que el Servicio de Salud Metropolitano Oriente, del que depende jurisdiccionalmente el hospital de Isla de Pascua, adaptó una casa para acoger a los isleños que por razones médicas llegan a Santiago, transformándose en un centro de sociabilidad de los migrantes y los radicados. Un sentimiento generalizado de los ancianos es volver a Rapa Nui, una vez dada su alta médica.

A partir de este panorama podemos concluir que en la actualidad la población rapanui de Isla de Pascua no ve satisfechas todas sus aspiraciones si continúa viviendo en el territorio insular; la migración se constituye entonces en una obligación ocasionada por las condiciones de vida local. 
Sin embargo, en los últimos años ésta ha comenzado a cambiar por las oportunidades económicas que el turismo ha impulsado (sobre todo en lo que respecta la pequeña hotelería).

Parte de la nueva migración, sobre todo de los jóvenes rapanui, se relaciona con la forma en que cómo los rapanui consideran su comunidad local. En efecto, muchos jóvenes señalan que la vida en la isla es monótona y que los mayores ejercen un estricto control sobre ellos. Migrar significa evadir ese control. Identificamos aquí el carácter aún cerrado de la sociedad insular en términos de las relaciones sociales, donde la ciudad aparece como un lugar de evasión. Sin embargo, como veremos a continuación, los isleños que emigran no salen de un círculo de conocidos cuando van al continente.

La instalación en el continente (principalmente en Santiago y Valparaíso) es explicada por los vínculos sociales consolidados tales como el matrimonio y la compra de una casa. La presencia del cónyuge continental, los hijos nacidos de esta unión y las propiedades adquiridas refuerzan un vínculo que denominaremos de "amarre" al continente. Se trata de un proceso de arraigo en el que una parte de la familia extendida consolida una propiedad disponible y abierta a las facciones de la familia de la isla. De este modo, la propiedad de una casa se transforma en una estructura de recepción que permite vincular a los miembros de la familia dispersa. Esto porque en tanto miembro de un grupo de parentesco, todo rapanui tiene derechos y obligaciones ante los otros miembros del grupo (cf. McCall, 1976; Muñoz, 2014a).

De esta manera, una nueva instalación en Chile continental resulta de un proceso familiar que responde a relaciones de lealtad.
Así, cuando la decisión de emigrar es tomada (individual o colectivamente), se activa la lealtad familiar. La instalación se caracteriza entonces en que un familiar es quien recibe a otro familiar. La gran mayoría de los casos observados resulta ser una relación de parentesco de tipo tío(a)sobrino(a). De este modo, el hermano del padre o de la madre asume un rol de tutor y abastecedor mientas su sobrino vive con ellos en el continente. De la misma manera, el sobrino asume el rol de hijo durante su estadía. Este tipo de relaciones nos recuerda aquella denominada ma'anga hānai o de delegación de crianza en las relaciones de parentesco rapanui. Estas relaciones permiten a una pareja (o de una madre soltera) que no pueda asumir el sustento de un hijo, pueda entregarlo al cuidado de otro grupo doméstico. En Rapa Nui conocemos dos mecanismos de delegación de crianza, una denominada pōki hanai, es decir, hijo alimentado, consistente en que el niño es incorporado a la familia receptiva de manera permanente; mientras que la forma ma'anga hanai, es una situación temporal. Por ello denominamos como esta última, la relación establecida entre un joven migrante y su familia de acogida ${ }^{12}$.

Lo anterior demuestra una estrecha relación entre parentesco y migración. Así, la presencia de familias ya instaladas en el continente permite un tipo de articulación. Cuando el nuevo inmigrante arriba, el resto de sus parientes y amigos ya residentes en el continente se encargan de incorporarlo en los círculos de conocidos y en las actividades donde los rapanui del continente se reúnen, activando con ello otras redes y espacios de solidaridad, tales como los curantos ceremoniales $u$ otras fiestas realizadas en el continente (Muñoz, 2007). 


\subsection{Irse a Tahiti: Pamatai como enclave.}

La migración rapanui a Tahiti debe ser entendida dentro de un proceso mayor de desplazamiento de población en Polinesia francesa iniciado en los años 70 (Fages, 1973; Fages, 1974; Rallu, 1994) y es diferente a la migración hacia Chile continental en al menos tres aspectos. En primer lugar, por su condición de extranjeros en territorio francés, los rapanui deben ajustarse a las normativas de extranjería que restringen el tiempo de permanencia. En segundo, lugar porque Tahiti representa un lugar de prosperidad donde encuentran una cultura polinésica que sienten propia, y en tercer lugar, por un aspecto inédito, la historia de las tierras de Pamatai.

La historia de diáspora rapanui en Polinesia, que ha sido escasamente estudiada, se inicia en 1871 cuando los misioneros de los Sagrados Corazones de Picpus abandonan Rapa Nui, provocando un gran éxodo de población rapanui hacia Mangareva y Tahiti (Anguita, 1986; McCall, 1976; McCall, 1996; McCall, 1997; Muñoz 2014b). En 1887, los misioneros vendieron a un grupo de veinticinco rapanui sobrevivientes de ese éxodo, una finca de 118 hectáreas ubicada en la escarpada colina de Pamatai, en el distrito de Faa'a en Tahiti, a dos kilómetros al sudoeste de Papeete, capital de Polinesia francesa. Estas tierras significan un vínculo memorial entre los rapanui contemporáneos, y la historia de diáspora y evangelización de mediados del siglo XIX.

Según los estudios de Patricia Anguita (1986) y Grant McCall (1996), el devenir de las colonias rapanui en Tahiti fue trágico. McCall (1996) cita a Arthur Baessler (1900), etnólogo y viajero alemán que conoció a los pocos sobrevivientes de Pamatai en el año 1897 y quien señaló que eran sólo 20 hombres, 11 mujeres y 13 niños y que muchos estaban afectados por la lepra. McCall (1996: 33) acota que "sólo uno de los 25 isleños que adquirieron tierras tuvo descendencia que aún vivía en Tahiti en 1960". Por su parte, Anguita (1986) explica que los matrimonios con otros polinésicos hicieron que los descendientes de dichos migrantes terminaron confundiéndose con el resto de la población polinésica. Sin embargo, en nuestra investigación de terreno y de archivos en Tahiti (2012 y 2013), pudimos determinar que al menos cinco grupos de parentesco del actual Pamatai poseen su origen familiar en la diáspora rapanui del siglo XIX (Muñoz, 2014b). Hoy constituyen familias tahitianas, donde algunas personas han conservado el recuerdo que un antepasado habría venido desde Rapa Nui a trabajar con los misioneros.

A pesar de la ruptura entre los rapanui de Tahiti y los de Isla de Pascua, producida por la política chilena de aislamiento de los años 20 (ver nota 3) y que impidió que las familias de un lado y del otro mantuviesen y perpetuaran un conocimiento mutuo, Pamatai aparece en Isla de Pascua durante todo el siglo $\mathrm{XX}$ como la motivación principal de la migración rapanui a Tahiti. Pamatai se yergue como enclave rapanui ya sea por la historia de diáspora y evangelización que hemos evocado, como por la relevancia que ha tenido tanto en la instalación como en las expectativas que los rapanui tienen de Tahiti.

En nuestra investigación sólo hemos podido constatar un viaje realizado en 1926, en el cual un grupo de quince personas partieron rumbo a Tahiti para "vender sus tierras" (Muñoz, 2014b). 
Hubo otros intentos entre los años 40 y 50 de salir de la isla en pequeñas embarcaciones. Según los testimonios recogidos por Englert (1960) y más tarde por Peteuil (2004), la existencia de estas tierras y familiares en Tahiti sirvió como argumento para intentar la travesía (Muñoz, 2010). En nuestra investigación de terreno en Pamatai pudimos registrar testimonios de algunos ancianos, habitantes del sector, quienes recordaban que los llegados en esa época fueron acogidos en el seno de algunas familias de Pamatai. Justamente aquellas que habían conservado el recuerdo de un origen rapanui.

Las tierras de Pamatai comenzaron a ser reclamadas por algunas familias desde Rapa Nui a partir de la década de 1970, momento en que se inicia la conexión aérea entre las dos islas (McCall, 1976; McCall, 1997; Muñoz, 2014b). Para reivindicar la propiedad, los rapanui emplearon como argumento los eventuales vínculos de parentesco con los antiguos propietarios, proceso que a nuestro modo de ver apela a una memoria sobre los orígenes familiares y a una manipulación estratégica de las genealogías. En este periodo (entre los años 1976 y 1990) se modifica la escritura de algunos apellidos, para hacerlos similares a los de los antiguos dueños de tierras, y se dividen los grupos de parentesco en función de la cercanía genealógica al antiguo dueño. Mediante esos procedimientos sólo cuatro grupos de parentesco rapanui han conseguido acreditar ser descendientes de alguno de los antiguos dueños, pero existen a la fecha otras seis reivindicaciones en curso en los tribunales de Papeete (Muñoz 2014b). Así, entre 1976 y 1990 muchos rapanui se instalaron en Pamatai y se encontraron con que el sector estaba densamente habitado, que las tierras había sido adquiridas por otras personas y que las célebres tierras rapanui se reducían a unas pocas calles de un barrio popular de Tahiti.

Desde las reivindicaciones de los años 70 estas tierras son objeto de conflictos entre los grupos de parientes que volvieron a ocuparlas. Los títulos de propiedad y el reparto de los usufructos monetarios por concepto de arriendos o ventas han generado fuertes tensiones $y$ desconfianzas entre los parientes que viven en Rapa Nui y aquellos que lo hacen en Tahiti.

Actualmente Tahiti ya no representa el lugar de abundancia como lo era hacia los años 70 , y que motivó en parte la migración rapanui. Actualmente los trabajos escasean, según el ISPF (Institute Statistique de la Polynésie française) la tasa de desempleo se ha duplicado en los últimos cinco años alcanzando un $21,8 \%$ en agosto de 2012 (ISPF, 2012). Las políticas migratorias se han hecho más estrictas, provocando una baja en la tasa de inmigración y un aumento en la tasa de emigración, particularmente hacia Nueva Caledonia.

En nuestra estadía en Tahiti durante el año 2009, pudimos registrar un total de 102 rapanui residentes en Polinesia francesa, de los cuales el $41 \%$ de ellos lo hacía en Pamatai. Estos últimos eran todos descendientes (en diversos grados genealógicos) de alguno de los antiguos propietarios, y habían llegado a Tahiti entre los años 1970 y 1980 a reclamar la propiedad de las tierras. En su mayoría, obtuvieron la nacionalidad francesa, ya sea por matrimonio o por naturalización. Consideramos en esta lista también a sus hijos, quienes si bien reconocen un origen rapanui, son de nacionalidad francesa, hablan el francés y entienden el tahitiano, lo 
que en un eventual retorno a Rapa Nui les significará trabas en cuanto a residencia y al ejercicio de sus derechos indígenas. En Pamatai es cada vez más notorio el hacinamiento y la imposibilidad de seguir dividendo las pocas tierras recuperadas.

El censo de 2002 de Polinesia francesa contabilizó para la comuna de Faa'a un total de 28.182 habitantes (ISPF, 2002), siendo la comuna más poblada de todo el territorio. Para el censo de 2007 habitaban 4.894 personas en el barrio de Pamatai, originarias de distintas islas del territorio (ISPF, 2007). Pudimos identificar además que aquellos que no tenían vínculos de parentesco con los rapanui que había recuperado algunas de las tierras en los años 70, se instalaron en otras comunas de Tahiti como Mahina, Pirae, Papara o incluso en otras islas de Polinesia francesa como Moorea, Bora Bora y Raiatea. La mayoría, contrajo matrimonio con tahitianos o franceses, lo que muestra la estrecha relación entre vínculo de parentesco y lugar de residencia.

Los rapanui en Tahiti se autoadscriben a una identidad polinésica y se autodenominan ma'ohi, término que los intelectuales tahitianos de ${ }^{-}$los años 70 utilizaron para hablar de la población autóctona de Polinesia francesa (Saura, 2008). Dada esta condición, creen tener derechos particulares para residir en Tahiti. Para el Estado francés, sin embargo, ellos son chilenos, por lo que necesitan de una visa de residencia para poder trabajar. Conocimos algunos rapanui que decían estar "sin papeles" (sin el permiso de residencia) por lo que si salían del territorio, no podrían reingresar. Ahora bien, los desplazamientos hacia Polinesia no están limitados a quienes acceden a los terrenos de Pamatai o a aquellos que se han instalado por matrimonio con tahitianos o franceses. Existe otro tipo de vínculo, que se establece por la participación de los grupos artísticos en los festivales de arte del Pacifico. Actualmente resultan emblemáticos para los rapanui los acercamientos a las Islas Marquesas y a Samoa (el festival de 2008 fue realizado en Samoa americana). Incluso en los últimos dos años, un grupo de danza de las Islas Marquesas ha participado como invitado en el festival estival de Rapa Nui.

Una de las características de este tipo de migración es que la ida y vuelta son relativamente rápidas, y sus participantes han retornado a Rapa Nui con una serie de relatos sobre estos lugares y sus formas de vida. Esto evidentemente ha tenido efectos relevantes sobre la configuración identitaria: construyéndose lo que denominaremos "una imagen de la Polinesia cercana". Esta imagen implica un sentimiento de pertenencia a un mundo histórico y cultural más amplio que la sola Isla de Pascua y donde el concepto ya evocado de ma'ohi, adquiera consistencia.

La participación en este mundo polinésico se ha estructurado como un lugar de alteridad. Algunos rapanui se han sentido más próximos a los habitantes de las Islas Marquesas que a los de Samoa, pero reivindican sobre todo, las particularidades de Rapa Nui. Otro de los efectos de estos desplazamientos tiene que ver con la representación que se hace de los enclaves. Así, Rapa Nui se concibe como un lugar tradicional y auténtico, mientras que Tahiti y Santiago son considerados espacios modernos y poco tradicionales. 


\section{Las experiencias del retorno y la reintegración en la comunidad local.}

Para los rapanui retornar a Isla de Pascua es siempre una posibilidad, particularmente cuando las expectativas de su estadía en el exterior no se cumplieron, o si las condiciones de vida cambiaron. En la medida que la actividad turística va adquiriendo mayor importancia en la economía insular, prometiendo un bienestar (monetario) inédito en la historia rapanui, hemos constatado un movimiento de retorno en aumento durante los últimos cinco años. Para comprender este novedoso proceso de articulación, es necesario analizar las formas que ha tomado la experiencia de retorno a Isla de Pascua y los mecanismos de integración en la sociedad insular.

El retorno ha tenido una forma de ir $y$ volver desde el lugar de residencia a la isla. Hemos podido ver que los jóvenes y los más ancianos son quienes experimentan el retorno de las maneras más extremas. Los jóvenes que viajan al continente por sus estudios $y$ tienen a su familia en la isla, vuelven durante las vacaciones estivales a Rapa Nui. Al final del verano (si han decidido continuar con los estudios) regresan al continente. En Rapa Nui se dice que generalmente vuelven cambiados y con una mentalidad "más continental", que se refleja en una actitud contestataria hacia el control de los mayores. Al contrario de aquellos jóvenes nacidos en la isla, los retornados son más proclives a valorar la forma de vida insular y sentirla propia. Por otra parte, los jóvenes nacidos en el continente que viajan a la isla son incorporados en una estructura de parentesco que implica una noción amplia del concepto de pariente y que conlleva una serie de obligaciones hacia el grupo de parentesco: respeto casi absoluto a los mayores y una serie de prohibiciones en lo que respecta las relaciones amorosas con otros isleños.

Un problema particular se produce cuando los rapanui nacidos en Tahiti cuyos padres se instalaron en la década de los 70 , intentan retornar. Tienen nacionalidad francesa y por tanto son considerados extranjeros desde la lógica estatal. Incluso si son bien acogidos por la familia extendida, su condición de extranjeros los deja fuera de los derechos consagrados por el Estado a los miembros del pueblo rapanui, en especial en lo referido a la propiedad de la tierra.

Para los ancianos las experiencias y deseos de retornar tienen una dimensión afectiva profunda: muchos ancianos radicados en el continente $o$ en Tahiti desean ser enterrados en Rapa Nui. En muchos casos es un deseo expresado en vida a alguno de sus hijos o nietos, quien asume entonces la responsabilidad y los costos de traer de regreso los restos de su padre o abuelo. En concordancia a la creencia rapanui en espíritus tutelares (McCall, 1998), conocidos como varua, traer de regreso los restos de un difunto se explica por el temor a que el espíritu del fallecido moleste al hijo que no ha cumplido con el deseo expresado en vida. Rapa Nui, además de estar poblada por los isleños, es el lugar de habitación de todos los espíritus tutelares (varua) pre-cristianos y nuevos. Los rapanui dicen que el espíritu de su padre o abuelo fallecido estará mejor en la tierra que le pertenece.

El retorno aparece como motivo de conflicto cuando aquellos que habiendo partido de Rapa Nui entre los años 70 y 90 , vuelven hoy reclamando derechos eventuales sobre tierras u opinando sobre los conflictos internos. 
Muchos rapanui, que dicen no haberse ido de la isla, les reprochan no haber ayudado desde el exterior cuando la vida en la isla era difícil. En este argumento se observa la importancia que adquiere el haber mantenido vínculos durante la estadía en el exterior. La experiencia del retorno, posee también un sustento material en las modalidades de herencia de las tierras. Ser considerado rapanui -por el hecho de tener al menos un padre que sea rapanui- está asociado a la propiedad de la tierra. Rapa Nui es uno de los pocos lugares en el mundo en que los niños nacen siendo propietarios teóricos. Si bien el ejercicio de estos derechos depende de la voluntad de sus padres y en la mayoría de los casos de los abuelos, que velan con celo los títulos de propiedad, hoy es el mismo Estado que asegura el acceso a la tierra bajo mecanismos establecidos por la llamada Ley indígena ${ }^{13}$.

De esta manera las memorias familiares que conservan la idea de un origen rapanui, como en el caso de jóvenes nacidos en Tahiti o en Chile continental, los sentimientos de afecto con la isla y su gente, como el anhelo de una vez muertos ser enterrados en Rapa Nui y los derechos de propiedad de la tierra, asegurados tanto por ley como por principio parental, son claves para entender el actual proceso de retorno y pensamos que funcionan como estructuras vinculantes a la sociedad insular.

\section{Rapa Nui como destino turístico: la llagada de extranjeros.}

En los últimos veinte años el número de residentes de origen continental ha aumentado y el devenir de Rapa Nui como destino turístico ha hecho de ésta un lugar de paso de personas de múltiples nacionalidades. El número de turistas ha aumentado en los últimos cinco años llegando a recibir 50.213 visitantes en 2012 (Servicio Nacional de turismo (SERNATUR), 2013), que en su mayoría provienen de Europa y Estados Unidos. Sin embargo, el aumento más considerable lo denota el número de turistas chilenos. Si en el año 2003 se contabilizaron 3.571 turistas nacionales (SERNATUR, 2004), para 2011 fueron 12.963 (SERNATUR, 2012) y aumentando en 2012 a 16.050 (SERNATUR, 2013). Rapa Nui se enfrenta hoy a un paisaje étnico (Apadurai, 2001) conflictual.

La migración desde Chile no ha sido objeto de un análisis profundo por parte de los estudiosos de Rapa Nui, ni por las agencias estatales de planificación. Se pueden encontrar algunas referencias en los trabajos de McCall (1975) y el estudio ya citado de Cristino et al. (1984). Como bien se señala en ambos trabajos, el arribo de chilenos continentales se inicia en el año 1966 con la instalación de las oficinas públicas, mucho antes del giro económico hacia la actividad turística. En nuestro estudio de los flujos migratorios hacia Rapa Nui pudimos determinar que los llegados en esa época eran en su mayoría hombres que fundaron sus propias familias con mujeres isleñas (recordemos la preferencia matrimonial hacia los no-rapanui). Algunos, habrían dejado a sus primeras esposas en el continente.

El arribo de chilenos continentales con posterioridad a los años 70 , ha estado asociado a proyectos de infraestructura, léase de modernización (Porteous, 1981). El primero en 1974, fue la construcción del Hotel Hangaroa, administrado por la Hotelera Nacional, 
Sociedad Anónima (HONSA) y que fue construido en un terreno que más tarde será objeto del conflicto de tierras más patente en Rapa Nui. Llegó un primer "contingente" de obreros e ingenieros, algunos de los cuales se instalaron en la isla. Luego, la ampliación de la pista de aterrizaje en 1986 provocó una nueva oleada migratoria que dio por resultado la formación de nuevas familias mixtas, y quizás, el momento de mayor auge de la emigración de población rapanui bajo la modalidad de los matrimonios mixtos que hemos señalado anteriormente (Muñoz, 2014a). Durante los años 90 la pavimentación del camino a Anakena tuvo efectos similares. En los últimos años, Rapa Nui ha conocido tres grandes proyectos de infraestructura: la construcción del nuevo Hotel Hangaroa (en medio de un conflicto por la propiedad de la tierra), la construcción de las oficinas de un nuevo banco y la construcción del nuevo Hospital. Sin embargo, la recepción por parte de la población rapanui de estos contingentes continentales ha cambiado en relación a los años 80 , cuando resultaba prioritario que los jóvenes rapanui encontrasen una pareja externa a la comunidad insular.

Hacia finales de 1998, Chile continental sufría los efectos económicos de la llamada crisis asiática. En esta época, el turismo en la isla comenzaba a mejorar y algunos chilenos llegaron a Rapa Nui, como algunos de ellos lo dicen hoy "a probar suerte". Para los continentales que llegaron con posterioridad al año 2000, la Isla de Pascua parecía presentarse como una oportunidad de mejorar sus ingresos. Muchos dicen haber alcanzado un nivel de vida que de haberse quedado en el continente no lo hubiesen logrado.
Si bien la percepción es que el turismo ha sido positivo para Rapa Nui, porque ha permitido mejorar las condiciones de vida de la población local, la sensación general de los isleños es que existe una "invasión de continentales". El malestar, sin embargo, se refiere no a la llegada de éstos propiamente tal sino más bien, hacia aquellos que llegados de turistas, se han quedado a vivir en Hanga Roa y montado sus propios negocios. El descontento aumenta si se ve que dichos chilenos continentales comienzan a acumular riqueza, manteniéndose fuera de las estructuras vinculantes del parentesco rapanui ${ }^{14}$.

Según los rapanui, los continentales que llegan hoy son de dos tipos: aquellos que arriban como obreros y los turistas. Estos conforman una categoría diferente y menos conflictiva. Por otra parte, los cónyuges continentales de los rapanui no son sujeto de preocupación dada su incorporación en las obligaciones reciprocas dentro del grupo de parentesco. De los obreros, según los rapanui, muchos se han quedado en la isla y han comenzado a invitar a sus familias a vivir a la isla, sin establecer alianzas con las familias rapanui. Se mantienen fuera de las relaciones de don contra-don que implican la pertenencia a un grupo de parentesco (McCall, 1980; Muñoz, 2014a). Es este aspecto quizás, el que genera más recelo entre los isleños.

Las relaciones de parentesco rapanui asumen un modelo de reciprocidad generalizada (Godelier, 1998; Lèvi-Strauss, 1949). Tanto en terreno, como en la literatura especializada (McCall, 1980) se observa que los parientes y aquellos que se consideran como tales, realizan diversas prestaciones a los otros miembros del grupo. 
Estas prestaciones pueden ser tan diversas como hacer circular alimentos (pescado, verduras, carnes) producidos tanto en la isla como fuera de ella, acudir a la convocatoria de trabajos colectivos, como la construcción de una casa, hasta asumir la responsabilidad de la crianza de niños (como lo indicamos más arriba). En este sentido, la riqueza se distribuye al interior del grupo de parentesco en forma de dones. De esta manera, si no se establece una relación de alianza con una familia rapanui, la persona (en este caso un continental) se resta de la red de intercambios y su riqueza, que a ojos de un rapanui debería ser repartida, se acumula individualmente. Sumado a lo anterior los rapanui dicen que los obreros han traído "malas costumbres" como los robos y el consumo de drogas. Esta explicación debe ser analizada en término de fronteras étnicas (Barth, 1976), ya que desde el punto de vista rapanui, se han puesto en tensión normas y conductas socialmente valoradas.

Asociado a este tipo de comentarios de la comunidad surgen espacios de tensión étnica, reflejados en la proliferación de estereotipos negativos de uno y del otro grupo. Algunos continentales consideran que "la isla sería perfecta si no fuera por los isleños" y los isleños atribuyen gran parte de las desgracias, como el "aumento de la delincuencia", a la presencia de continentales. El tema adquiere connotación política cuando por un lado los chilenos continentales reclaman el derecho de habitar en Isla de Pascua por ser ella "territorio nacional", mientras que los rapanui reclaman el derecho de decidir "quién entra y quién no". Para el año 2014 se espera el ingreso de un proyecto de ley al Senado que pretende restringir la circulación de personas al territorio insular, con el objetivo de preservar el delicado ecosistema en la isla ${ }^{15}$.

En nuestra última estadía en Rapa Nui (2014) pudimos contabilizar a solo doce chilenos continentales que había llegado en 1966. Los restaurantes y locales comerciales administrados por chilenos continentales abundan y la migración venida desde el continente está lejos de terminarse. En terreno pudimos notar también que a los chilenos continentales se les han sumado ciudadanos peruanos, colombianos, cubanos y algunos polinésicos provenientes de Wallis, Tahiti e Islas Marquesas.

\section{De cómo los vínculos son mantenidos, flujo de mercancías.}

Bien lo muestra Marcus (2001), los flujos de personas van siempre acompañados de flujos de cosas o mercancías. Nuestra investigación demuestra que estos objetos contribuyen a mantener ligadas las facciones familiares dispersas. Pensamos que con ellos los rapanui establecen una modalidad de ser comunidad más clara. Siguiendo a Maurice Godelier (1998), los vínculos entre las personas se actualizan en el intercambio de objetos, constituyendo una red de relaciones sociales en términos de obligaciones recíprocas. Los vínculos que hemos constatado en terreno y que presentaremos a continuación, dan cuenta de la instalación de Isla de Pascua en un circuito global de intercambios dentro de un mercado específico y también del carácter relacional de Rapa Nui hacia Chile y Polinesia francesa. 


\subsection{Flujos desde Chile continental: los bienes esenciales.}

Los flujos de mercancías desde Chile continental poseen una característica que nos parece significativa. Se trata por un lado del aprovisionamiento de bienes de subsistencia y por otro de bienes de alto valor cultural. La ex Empresa Nacional de Abastecimiento de Zonas Aisladas (EMAZA)-cerrada en 2012- señalaba en su informe anual para el año 2008 que su objetivo hacia Isla de Pascua era "asegurar el aprovisionamiento ininterrumpido de productos esenciales para la población" (EMAZA, 2009: 6), tales como carnes, verduras, alimentos en conserva, harina, azúcar, sal, pastas, arroz, entre otros. La importancia de EMAZA en Rapa Nui hasta hace pocos años, conllevó a que los isleños consideren el aprovisionamiento como un deber del Estado. Esto sin dudas, posee una connotación política e histórica. Los rapanui argumentan que el Estado se comprometió con el desarrollo y bienestar económico y social de la isla desde el día de la anexión en $1888^{16}$. En ese sentido, y recordemos lo referido por Goñi (1983), el acceso a bienes venidos del exterior vino a ser sinónimo de desarrollo.

Esta percepción local tiene otro efecto asociado. Se trata del valor que los isleños dan a las mercancías que arriban del continente en comparación a las locales. En primer lugar, los alimentos continentales son consumidos en el cotidiano, en ello no se cuestiona ni el cambio alimenticio ni los efectos de dependencia hacia Chile continental. En segundo lugar, parece cada vez más claro que la dependencia del continente ha generado la reducción de la producción de alimentos locales y una fuerte dependencia de la actividad turística. El estudio de Ramírez (2010), muestra bien que esta relación ambivalente con el Estado ha puesto en tensión la soberanía alimenticia de Isla de Pascua. En terreno se observa que las actividades económicas tradicionales como la agricultura de pequeña escala y la pesca poseen un valor identitario ya que algunas familias se definen entre otras características por ser algunas de pescadores y otras de agricultores. Por otro lado, los productos alimenticios locales comienzan a tener una connotación ritual. Ellos solo son consumidos en las grandes fiestas comunitarias realizadas por motivos religiosos como los bautizos, y matrimonios o durante el ciclo de los umu atua, festividades católico-rapanui para los santos patronos (cf. Montecino, 2010; Ramírez, 2010).

Resulta interesante constatar que algunas mercancías llegadas del continente poseen un alto valor identitario y dan cuenta de un proceso de selección cultural. Se trata en particular de bienes de valor simbólico como los pareo (trozos de tela estampadas con motivos rapanui), conchas para fabricar collares (que las mujeres venden a la salida del aeropuerto de Hanga Roa), y la mayoría de las plumas con las que hoy se fabrica la vestimenta e indumentaria considerada tradicional.

Los pareo y las conchas son comprados en el barrio Patronato de Santiago, donde se comercializan las telas importadas desde Asia. El barrio Patronato es conocido por ser un barrio de inmigrantes de origen árabe, chino y coreano. Las telas que los rapanui compran, son fabricadas en China y también en Tailandia, y las conchas recolectadas en Vietnam o Taiwán. 
Luego, las telas son estampadas y enviadas a Rapa Nui donde serán vendidas como pareo y las conchas hiladas en collares.

El caso de las plumas nos parece emblemático. Los rapanui que habitan en Santiago las compran en grandes cantidades a los criaderos de pollos y empresas de fabricación de almohadas, y las envían a sus familiares en la isla para la confección de las faldas, coronas $u$ otros artefactos que forman el atuendo tradicional. De este modo la vestimenta tradicional rapanui es el resultado -y el reflejo- de esta serie de flujos, y están lejos de ser survivals de un pasado lejano. Constatamos así la flexibilidad e ingeniosidad en el proceso de fabricación identitaria, el que se expresa en diferentes esferas de la vida social isleña y que parece ser uno de los rasgos más característicos de la sociedad rapanui (cf. Andrade, 2004; Muñoz 2007; Andreassen, 2009). Hoy los emblemas empleados en la performance identitaria (Andrade, 2004), son productos de una red de circulación de objetos y personas. La facción familiar asentada en Santiago cumple con dotar de bienes para la reproducción identitaria a la facción localizada en la isla (Muñoz, 2007; Muñoz, 2010).

\subsection{Las cosas más bellas llegan desde Tahiti (de más allá al poniente).}

Del otro lado del océano, de Tahiti a Rapa Nui, la circulación de mercancías evidencia ante todo, la vinculación y pertenencia a un mundo polinésico más amplio. En general, lo que llega de Tahiti es considerado de un alto valor estético y hacen de Isla de Pascua un lugar "polinésico" tanto a los ojos del turista como al de los mismos isleños.
Los bienes de "origen" polinésico arriban a Rapa Nui de tres maneras: traídos por los rapanui que han viajado, enviados por los miembros de la familia ya radicados, o exportados por comerciantes. La modalidad más común sin embargo, es la que los isleños llaman "matute". Este término es definido por la Real Academia de la Lengua Española como la introducción de mercancías de manera clandestina, es decir como contrabando. Sin embargo, en Rapa Nui designa la venta en pequeñas cantidades de productos traídos desde Tahiti (o el continente) sin que estos sean vendidos en locales formalmente establecidos. Preferentemente actividad femenina, las "matuteras", son quienes traen los productos y los venden, bien en la calle o a locales comerciales ${ }^{17}$.

Una constatación interesante que hemos podido observar en terreno es que el "matute" aparece hacia los márgenes de las relaciones de reciprocidad del grupo de parientes. Es decir, las relaciones de mercado aparecen cuando ya no se es pariente, y por tanto las "obligaciones asociadas", dejan de tener importancia.

Poco a poco ha comenzado a proliferar un mercado formal e informal ("matute") de mercancías polinésicas. Los objetos más abundantes son los pareo. Los pareo tahitianos son considerados por los rapanui como más bellos y exclusivos que los propios. Sin embargo, hemos podido constatar que todos los pareo "tahitianos" habían sido fabricados en Tailandia. Con los pareo "made in Thailand" nos situamos frente a un proceso de circulación global de mercancías, que al igual que las conchas o los pareo de Patronato, va más allá del circuito Rapa Nui-Santiago-Tahiti. 
Desde Tahiti se exporta también el monoi, aceite de coco mezclado con flores, utilizado en Rapa Nui generalmente por las mujeres, quienes le atribuyen altos poderes sensuales. Son además los olores que se consideran característicos de la Polinesia. La importancia de este producto nos parece capital para entender cómo en Rapa Nui se construye un imaginario, una noción de la Polinesia. No dudamos que estas dos características asociadas al monoi sean producto de las representaciones que se han construido de Tahiti y la Polinesia como un lugar de sensualidad (cf. Tchekézoff, 2001) y que de alguna manera también se encuentran presentes en Rapa Nui.

Las carteras de fibra vegetal trenzadas o de telas, son una de las nuevas modas importadas desde Tahiti, aunque ya han dado lugar a la fabricación local. Los collares de conchas, o de perlas negras -otrora gran fuente económica en Polinesia francesa- son en Rapa Nui bienes de prestigio por excelencia. Los comerciantes y las "matuteras" han identificado también un nicho de mercado en la marca tahitiana Hinano. Las camisas Hinano o cualquier otra camisa venida de Tahiti son apreciadas por los hombres, quienes las portarán en ocasiones especiales o en contextos considerados "elegantes". Con estas prendas identificamos un proceso de identificación similar al descrito para el monoi. El ícono de la marca es el dibujo de una mujer de tez morena, que aparece sentada en una playa con palmeras y vestida con un pareo rojo, su cabellera negra adornada con una corona de flores blancas. Hinano es en Rapa Nui sinónimo de Polinesia.

Otro producto es el tabaco marca Bisson que destaca, según dicen los rapanui, por ser "más fuerte que el chileno".
Por último, las plumas, de una mayor gama cromática que las llegadas del continente son escasas pero comienzan a ocupar una plaza en la fabricación de los trajes tradicionales. Pensamos que estos productos son apreciados al evocar un vínculo particular con Tahiti, acercándolo a Rapa Nui, pero también porque plantean una relación diferencial hacia Chile continental. Mientras que las relaciones con éste último son definidas en términos de responsabilidad del Estado, con las mercancías de Tahiti reconocemos un ensamblaje identitario y afectivo. Ellas hacen de Rapa Nui un lugar polinésico.

\subsection{Flujos de Rapa Nui al exterior: los recuerdos del viaje y los regalos para la familia.}

Consideramos finalmente la circulación de mercancías desde Rapa Nui al exterior. Así los productos locales y relocalizados (siguiendo a Appadurai, 2001) son inscritos dentro de otros desplazamientos. Se trata de las cosas que llegan a Rapa Nui como materias primas (conchas o plumas, por ejemplo) y vuelven a Chile continental (o más allá de) transformados, en objetos turísticos icónicos de Rapa Nui. Así, de la isla salen toda suerte de collares fabricados con conchas venidas del sudeste asiático, pareo fabricados en Tailandia, coronas de plumas continentales, tallados en madera, entre otros ${ }^{18}$.

Además de este circuito, de Rapa Nui salen otros bienes ligados a las obligaciones con el grupo de parentesco: se trata de mercancías con un contenido afectivo. Así, es común que cuando los estudiantes vuelven al continente 
para continuar sus estudios lo hagan portando regalos de sus familiares y para sus familiares del continente. Los rapanui arriban con materiales empleados como emblemas identitarios, tales como el kie'a, el pigmento con el que se pintan el cuerpo para sus presentaciones artísticas, las que realizarán en el continente durante el año como forma de exhibición de la cultura de la isla; con estatuas de madera en forma de moai, pedazos de coral, o trozos de tapa, la tela tradicional ${ }^{19}$. Interesante resultó constatar en terreno que los rapanui, tanto en Santiago como en Tahiti, adornan las paredes de sus casas con estos objetos. Al ser consultados dicen que "son recuerdos de mi tierra". Es importante señalar también el carácter de regalo de estos bienes ya que portan en ello un valor afectivo. En general, sirven para agradecer ya sea a continentales que los acogieron o a otras personas que hayan hecho "favores" durante una estadía en el continente. Si imaginamos el caso de un pareo fabricado en Tailandia, comprado por un rapanui en Tahiti y llevado como regalo a Isla de Pascua, da cuenta a la vez de una red de intercambios globales pero también de relaciones a nivel local y familiar, lo mismo que una pequeña estatua en forma de moai que será regalada a algún amigo continental o tahitiano.

El principal corolario del flujo de mercancías hacia y desde Rapa Nui es comprender cómo la comunidad translocal se articula. En ese sentido, no basta con que los miembros de un grupo salgan de su lugar de origen para establecer este tipo de comunidad, lo importante es que los miembros permanezcan ligados, a pesar de la distancia. Como hemos señalado, estos vínculos son por un lado, el compromiso de los rapanui en recibir a sus parientes cuando viajan y por otra parte, hacer circular regalos y productos de alto valor identitario. Muchos de estos objetos serán desplegados en contextos urbanos para mostrarse como rapanui frente a un "otro", sea chileno continental o tahitiano, ayudando a construir una "particularidad" rapanui (Muñoz, 2007; Muñoz, 2010).

\section{Representaciones del exterior, la circulación de información.}

Finalmente queremos referirnos a la circulación de información sobre acontecimientos ocurridos en el exterior, ya que corresponden también a diferentes representaciones e ideas que describen el mundo fuera de la isla. Un hecho interesante es que crean un imaginario, una serie representaciones sobre una realidad dada (Godelier, 1984). Este imaginario viene a ser parte de un nuevo espacio de alteridad entre Rapa Nui y el exterior. En este proceso de circulación de información la sociedad rapanui activa mecanismos de cerradura y de control, apoyándose en el carácter insular de la sociedad rapanui contemporánea.

El impacto de los medios de comunicación es otro de los temas desatendidos en la literatura especializada sobre Rapa Nui, y que merece un análisis detallado. Presentaremos a continuación algunos elementos que nos parecen importantes.

En nuestros trabajos de campo hemos podido constatar la existencia y profusión de una serie de ideas sobre el exterior que tienen por fuente la información aparecida en los medios de comunicación de masas, en su mayoría, de origen continental. 
El principal efecto ha sido construir representaciones sobre Chile continental y a veces, sobre otros países.

En Isla de Pascua existen tres señales de televisión que transmiten desde el continente y una local. De tiempo en tiempo los turistas dejan los periódicos entregados en el avión y existen dos frecuencias de radio, una local y otra continental. Por último, existe una limitada y lenta conexión a internet. Con estos recursos tecnológicos, la sociedad insular se mantiene ligada a los flujos globales de información.

En lo que respecta la información "interna", esta circula bajo la modalidad del "boca en boca", y es una información de tipo personal sobre los miembros de la comunidad. Su circulación es siempre en base a rumores y su credibilidad está determinada por expresiones del tipo "yo lo vi", o "yo escuché". Podemos constatar la existencia de un sistema de comunicación montado sobre una "comunidad de conocidos" que deja en evidencia dos características de la sociedad rapanui descrita por los isleños: las redes de parentesco y el conocimiento mutuo de sus miembros (Muñoz, 2010). Nos resulta relevante que esta información personal se transmita en la lengua nativa, quedando excluida por ende la población de origen extranjera (incluida en esta categoría los chilenos continentales).

Por otro lado, es justamente la circulación de esta información en términos de rumores, la que activa diferentes mecanismos de control del comportamiento que fue evocado como uno de los motivos que los jóvenes tenían para intentar vivir una temporada fuera de la isla. Consideramos que en este plano existe un proceso de "cerradura" de la comunidad sobre sí misma y que tiende a juzgar el comportamiento tanto de los miembros internos de la comunidad como el de los extranjeros. En Rapa Nui muchas veces las personas cuidan su comportamiento por miedo de ser protagonistas de los rumores que circulan.

Señalamos más arriba que los medios de comunicación del continente han construido representaciones sobre este último. Por otro, agregamos que las mismas narraciones de las experiencias de viajes (como la participación en los festivales de arte) aportan con las suyas. Estas narraciones hacen circular un ensamble de ideas que oponen a Rapa Nui con el continente y con Tahiti.

Para los rapanui, Santiago es un lugar peligroso, porque las personas, los tiempos y, en general, la atmósfera urbana son asociados a la agresividad y al sufrimiento. Según ellos, el tiempo pasa rápido y la gente es más triste y no se conoce entre sí. Esta evaluación nos remite a la percepción de la vida insular como un espacio de protección. En complemento a ello los "medios" refuerzan la idea de peligrosidad, dada la preponderancia de este tipo de información en los noticieros chilenos.

Al contrario, los rapanui ven a Tahiti como un lugar próspero en términos materiales gracias al actuar de Francia como potencia mundial, pero son críticos al decir que ha perdido sus tradiciones polinésicas, a diferencia de Rapa Nui donde se habrían conservado. Esto puede ser consecuencia de los años de abandono estatal hacia la sociedad insular, pero también por el rápido proceso de invención identitaria y valorización de lo considerado como propio que actualmente vive Rapa Nui (en un contexto en el cual el turismo, llamado cultural, requiere de objetos exóticos). 
En el discurso identitario rapanui, constatamos una imagen idealizada de la propia sociedad, un pasado megalítico glorioso gobernado por reyes que conocían la escritura, todos elementos que en el discurso político de la identidad forman parte de los rasgos a enaltecer. Es por ello que los rapanui se ven a si mismos como más auténticos y respetuosos de sus tradiciones que los tahitianos.

Las dos ciudades serían entonces ejemplos para generar contrastes. Eriksen (1993) denomina a este proceso como "dicotomización" a través del cual los rapanui identifican y definen lo propio y lo ajeno. Según Alain Babadzan (2009), en los últimos treinta años todas las sociedades del Pacífico han iniciado procesos de invención de la tradición (o de relación moderna a la cultura), en la cual las representaciones idealizadas del pasado vienen a formar parte de las expresiones materiales de una identidad en el presente.

De este modo, los diferentes flujos de información hacen que la sociedad rapanui se abra o cierre en relación a los acontecimientos internos y externos. Así, el aspecto más relevante de este panorama de circulación de representaciones, es que muestra que la sociedad insular es altamente abierta y receptiva hacia muchos acontecimientos externos, pero que ha encontrado en su red de circulación interna un mecanismo de resistencia que interpreta no solo lo que llega de afuera, sino también los hechos internos. Los medios de comunicación como las narraciones de viajes instalan en la sociedad insular momentos de alteridad que van construyendo un discurso sobre la "autenticidad" de Rapa Nui.

\section{Conclusiones: Identidad y ensamblaje, cuando no hay sentimientos de ruptura.}

En general la migración ha sido considerada un factor importante en los procesos de aculturación, sin embargo, nosotros hemos propuesto que ésta genera procesos de construcción identitaria y una forma de comunidad que trasciende el espacio geográfico finito. Los diversos mecanismos de articulación comunitarios que identificamos como las redes de parentesco, las relaciones de don contra-don, o las representaciones sobre el exterior, crean contextos de alteridad y de afirmación identitaria.

Cuando los rapanui hablan de sí mismos se autodefinen como un pueblo polinésico, y aquellos que han vivido en Tahiti, utilizan el término de mā'ohi. Este concepto integra a la sociedad rapanui en un universo cultural, histórico e incluso genealógico más amplio que la isla misma. Por otro lado, Chile continental es representado como un otro radicalmente diferente. Los rapanui argumentan no tener nada en común con la sociedad chilena aparte de una nacionalidad y mucho menos con las otras sociedades indígenas del país. Al mismo tiempo, un sentimiento de pertenencia y autenticidad se consolida cuando se ven enfrentados a otras sociedades de Polinesia, principalmente a tahitianos. Los rapanui, aūnque considerándose ma'ohi, se piensan diferentes a los tahitianos. Argumentan que estos últimos poseen una forma de vida urbana y moderna en términos tecnológicos, mientras que en Rapa Nui se mantiene una comunidad de relaciones cara a cara y que conserva una memoria de un origen común. 
En segundo lugar, la circulación de mercancías aporta elementos importantes para mantener los modos de vida en Rapa Nui y también para la fabricación de emblemas identitarios. La circulación de mercancías, en base a las relaciones de reciprocidad y lealtad familiar, permite mantener los lazos más allá del territorio insular y refuerza el sentimiento de pertenencia al colectivo.

Por otra parte, la dependencia hacia Chile continental en el plano económico, educativo y sanitario construye una relación diferenciada con Tahiti. Con Chile hay una "dependencia esencial" mientras que con Tahiti, hay un deseo de construir y perpetuar vínculos. La circulación de productos manufacturados conduce a la incorporación de Rapa Nui en una circulación global de mercancías las cuales llegan a tener un valor particular en los procesos de reafirmación identitaria.

Finalmente, los flujos de información y las representaciones del exterior hacen que la "comunidad de conocidos" se cierre sobre sí misma al tensionar los valores sociales que los rapanui consideran importantes. Si el continente es peligroso (como lo muestran los medios de comunicación), los rapanui establecen una frontera (Barth, 1976) con los continentales en la isla. Ello podría ayudar a entender las actuales tensiones migratorias que señalamos al inicio de este artículo. Por otra parte, si los mā‘ohi de Tahiti han "perdido sus tradiciones" por la influencia de Francia metropolitana, los rapanui dicen que deben proteger las suyas y evitar que su sociedad se transforme de la misma manera, instalando diferentes procesos de orden político-identitario para frenar el control del Estado y adquirir más participación en las tomas de decisiones ${ }^{20}$.
Estos procesos de articulación nos revelan entonces una comunidad que sobrepasó los límites de su insularidad geográfica y que se mantiene unida a través de lazos de parentesco y de reciprocidad como obligación social. Así, entre los rapanui que viven dispersos no existe un sentimiento de ruptura con la comunidad de origen y su territorio, al contrario existe la intención de mantener las relaciones que los unen, incluso después de la muerte.

Epelie Hau'ofa (1993) señaló que las sociedades del Pacífico habían salido de sus pequeños espacios insulares en un proceso que denominó "ampliación del mundo". Este lo entendemos como una experiencia fenomenológica de desbordamiento de las fronteras físicas y geopolíticas por relaciones imaginarias o reales con el exterior. En este caso, las sociedades amplían su territorio imaginado, se extienden a través de conexiones familiares hacia otras experiencias de vida $y$ otras maneras de vivir; así como también hacia nuevos conocimientos y oportunidades. En este sentido, para el caso que analizamos, se genera el conocimiento empírico de dos mundos diferentes, el continental y el polinésico.

Pensamos que la ampliación de mundo y las comparaciones generadas en el momento de los desplazamientos son dos maneras de estructurar nuevas formas culturales fundadas simultáneamente en nociones de arraigo y de movilidad. Sahlins explica que:

\footnotetext{
"El masivo fenómeno de la migración circular crea un nuevo tipo de formación cultural: una comunidad bien determinada pero sin entidad, que se extienden, más allá las fronteras culturales y soberanías nacionales, de un centro rural del tercer mundo hasta esos enclaves de "hogares en el extranjero" de las metrópolis, todo
} 
unido en un ir y venir de bienes, de ideas y de pueblos en movimiento." (Sahlins, 2007:329)

Si consideramos que las experiencias de movilidad se caracterizan por un ir-venir permanente de personas, de mercancías, de bienes valorados, de información, de relaciones de lealtad familiar y compromisos sociales, Rapa Nui como comunidad y lugar de memoria, es pensada a través de sentimientos de continuidad cultural y de permanencia en el tiempo. Ambos criterios resultan capitales para establecer un discurso sobre la autoctonía (Muñoz, 2014a). En este sentido, la sociedad rapanui translocal puede ser considerado como una totalidad. Sahlins señala:

“(...) como una totalidad, la sociedad translocal está centrada en sus comunidades indígenas y orientadas para ellas. Los inmigrantes se identifican con sus parientes en la región de origen, y es a través de esa identificación que se asocian transitivamente entre si en el extranjero. Esos habitantes de la ciudad y del mundo exterior permanecen ligados a sus parientes en la tierra natal (...)" (Sahlins, 1997: 115-116).

De este modo, la comunidad insular dota de ciertos elementos materiales, visiones de mundo y memorias a los rapanui que viven en el continente o en Tahiti sostenidos en sentimientos de arraigo. Los rapanui que habitan en el continente o en Tahiti aportan a la comunidad insular otros bienes culturalmente valorados (como las plumas), otras ideas sobre el mundo (como la pérdida de tradiciones) y otras memorias a través de experiencias de movilidad (como la recuperación de las tierras de Pamatai).

La interdependencia entre los lugares de residencia nos parece clara. Las características de la sociedad rapanui de hoy son el resultado de una dinámica de los flujos. En este sentido Sahlins agrega:

“(...) la sociedad translocal puede perfectamente persistir cuando existe una diferencia cultural entre lo rural y lo urbano, o, de manera más general, entre la tierra natal indígena y los lugares metropolitanos en el exterior. Los dos sectores permanecen entonces interdependientes y culturalmente centrados en la tierra natal." (Sahlins, 1997: 121).

Nuestra perspectiva de visualizar a Rapa Nui como un centro unido a sus enclaves exteriores, nos ha permitido ir más allá de los límites geográficos de la isla y comprender que, finalmente, el lugar considerado como el más aislado, socialmente hablando no lo es. Vemos que la sociedad insular actual es el resultado de una red de relaciones históricas, familiares y comerciales entre tres lugares de residencia. Esta perspectiva nos ha permitido comprender cómo se construye la interdependencia entre los lugares, cómo se crean determinados conocimientos y representaciones, y cómo estos permiten contrastar las diversas experiencias de vida que van definiendo las formas de autorepresentación de una sociedad y la percepción del otro.

\section{Notas}

\footnotetext{
${ }^{1}$ Este trabajo forma parte de la investigación doctoral "Entre enracinement et mobilité: l'identité rapanui contemporaine (au-delà l'île de Pâques, vers le Chili continental et la Polynésie française)", para obtener el grado de Doctor en Ciencias Sociales, estudios comparativos en antropología, sociología e historia. Ecole de Hautes Etudes en Sciences Sociales, France Centre de Recherche et de Documentation sur l'Océanie (UMR 7308).

2 Empleamos la palabra "rapanui" como adjetivo y para hacer referencia al gentilicio de los habitantes autóctonos de Isla de Pascua. El término "Rapa Nui” es exclusivamente utilizado para referirse al territorio insular.
} 
${ }^{3}$ Aquí los miembros de los otros pueblos indígenas contemplados en la pregunta censal, son considerados como chilenos continentales.

${ }^{4}$ Debido a una serie de irregularidades detectadas en el proceso de recolección de datos, el Censo 2012 fue descartado como instrumento de planificación de políticas públicas. Se espera la realización de un nuevo censo para 2017. Por esta razón las cifras oficiales son aquellas del Censo 2002. Para obtener cifras actualizadas hemos recurrido a las estimaciones realizadas por el Instituto Nacional de Estadísticas (INE) que pueden ser consultadas en Internet. La información se encuentra disponible en el sito de la Biblioteca Nacional del Congreso (BNC) Para mayores detalles ver: http://reportescomunales.bcn.cl/2013/index.php/lsla_de_Pascua

${ }^{5}$ La principal razón esgrimida por las autoridades de la época para esta prohibición, fue la presencia de la lepra en parte de la población isleña. Esta política permitió mantener una mano de obra estable y de bajo costo a la Compañía Explotadora de Isla de Pascua, empresa ganadera que arrendaba el territorio insular al Estado de Chile. Para más antecedentes referirse a Weisner \& Fajreldin (2003), Muñoz (2007), y más recientemente Foerster \& Montecino (2013).

${ }^{6}$ En Rapa Nui, continente o "conti" refieren al territorio chileno continental; de la misma manera, continental o "conti" refiere a sus habitantes.

${ }^{7}$ Marcus (2001) propone una serie de técnicas para registrar el desplazamiento de persona, de objetos y de ideas. Nos propone que utilizando diferentes tipos "biografías" es posible develar los procesos de "anclaje" espacial de los procesos observados. Las estrategias de mapeo sugeridas por Marcus son: "Seguir a las personas, seguir los objetos, seguir la trama, la historia o la alegoría, seguir la biografía, seguir el conflicto y realizar una etnografía estratégicamente situada" (Marcus 2001: 118-121).

${ }^{8}$ La presencia de isleños en el ejército es la más antigua relación de Rapa Nui y el Estado chileno, un completo estudio se encuentra en: Departamento de Historia Militar (2006) y más recientemente en Moreno Pakarati (2012).

${ }^{9}$ El Estado chileno entregó en arriendo las tierras de Rapa Nui para la crianza de ovinos (entre 1896 y 1953), primero a Henry Merlet, comerciante francés radicado en Valparaíso (desde 1895) y posteriormente a la Compañía Explotadora de Isla de Pascua Williamson Balfour (1903 hasta 1953), momento en que la Armada se hace cargo de la administración de la Isla y de la estancia. Para mayores antecedentes referirse a Seelenfreund et al. (2004), y al completo estudio compilado por Cristino \& Fuentes (2011). Recientemente Fuentes (2013), compila un segundo volumen con artículos que analizan diferentes aspectos del "ciclo ganadero" en Isla de Pascua

${ }^{10}$ El término "pascuense" es utilizado en Chile continental para hacer referencia a la población nativa de Rapa Nui. Si bien hasta los años 90 funcionó también como etnónimo reivindicado por los mismos rapanui, actualmente ha sido remplazado por el término "rapanui", como categoría identitaria.

${ }^{11}$ En 1965, el Estado de Chile firma un convenio con la
Fuerza Aérea norteamericana para la instalación de una base rastreadora de satélites. En junio de 1965 llegó el primer contingente de militares norteamericanos y en agosto un carguero portando equipamiento y materiales de construcción junto a una dotación de cerca de 1000 hombres, que permanecían embarcados, siendo 400 los que quedaban en tierra (Cristino et. al., 1984). En este periodo Rapa Nui forma parte de los intereses geopolíticos norteamericanos en el contexto de la Guerra fría. Esta base fue una más de varias instalaciones militares norteamericanas en el Pacífico (Muñoz 2010).

${ }^{12}$ En otras sociedades polinésicas la delegación de crianza se denomina fa'amu, que al igual que el término rapanui hanai significa "alimentar". Para un análisis de este tipo de relaciones en Rapa Nui ver Zurob (2010). Un completo estudio sobre niños fa'amu en Polinesia francesa puede ser consultado en APRIF (1993).

${ }^{13}$ Nos referimos a la ley 19.253 . Esta ley establece en su artículo 12 la protección de las tierras indígenas prohibiendo la compra-venta a personas no-indígenas.

${ }^{14}$ Para un análisis completo de las relaciones de parentesco en Rapa Nui ver McCall (1976); McCall (1980). Más recientemente Muñoz (2014a).

${ }^{15}$ Hace algunos años se formó en Rapa Nui una organización informal compuesta por mujeres rapanui y continentales residentes desde la década de 1960-80. Este grupo se ha dedicado a sensibilizar sobre la necesidad de regular el tránsito y radicación de continentales en territorio insular. Ellos han sido asesorados por juristas y por organismos internacionales de derechos humanos de pueblos indígenas, de modo que los fundamentos para tal solicitud pudieran estar emparentados con procesos similares en el resto del mundo.

${ }^{16}$ Rapa Nui pasó integrar el territorio chileno en 1888 con la firma de un tratado entre el ariki Atamu Tekena (y sus consejeros), y el capitán chileno Policarpo Toro. Según la interpretación de este tratado, el Estado chileno se presentaba como "amigo del lugar" (mau te hoa kona) comprometiéndose en el desarrollo de la isla y respetando a la vez los cargos de autoridad existentes en ese momento. El sentir general de las organizaciones rapanui a lo largo de años es que el Estado no ha cumplido con ese acuerdo. Para comprender en profundidad estos acontecimientos referirse a McCall (1996), Seelenfreund et al. (2004), Escobar \& Lagos (2009), Delsing (2009), Cristino \& Fuentes (2011).

${ }^{17}$ No sabemos cómo el término "matute" llega a Rapa Nui, pero sin duda es producto de los contactos con Chile continental, donde el término posee la misma connotación.

${ }^{18}$ Francisco Torres (2012) presenta un interesante análisis sobre la producción de artesanía en Rapa Nui y los circuitos de mercado por las que circulan.

${ }^{19}$ Tapa hace referencia a las telas confeccionadas tradicionalmente tanto en Rapa Nui como en el resto del Pacífico a partir de la corteza interior de determinadas plantas de la familia de las moráceas, principalmente la morera de papel (Broussonetia papyrifera). En contextos tradicionales pre y pos cristianismo, se empleaba para cubrir objetos ceremoniales y personas de poder o de rango. 
En algunas sociedades las telas de tapa siguen siendo objetos de intercambio ceremonial. Un completo estudio sobre los objetos textiles rapanui se encuentra en Seelenfreund (ed.) (2013).

${ }^{20}$ Para un análisis detallado de las acciones de reivindicación político-identitarias ver Delsing (2009); sobre la búsqueda de mayores espacios de autonomía política referirse a Escobar \& Lagos (2009).

\section{Referencias bibliográficas}

Andrade, P. (2004) Artífices del imaginario. La puesta en escena, una aproximación a la construcción de identidad Rapa Nui. Tesis para optar al grado de Licenciado en Antropología y al título profesional de Antropólogo Social. Santiago: Escuela de Antropología, Universidad Academia de Humanismo Cristiano.

Andreassen, O. (2008) When Home is the Navel of the World. An ethnography of young Rapa Nui between home and away. Tesis de Doctorado. University of New South Wales.

Anguita, P. (1986) La migration Rapanui à Tahiti et Mangaréva (1871-1920). Mémoire DEA : Université de Rennes 2

APRIF (1993) Regards sur l'enfant fa'a'amu. L'adoption en Polynésie, entre tradition et modernité. Association Polynésienne de Recherche, Intervention et Formation. Papeete, Tahiti.

Appadurai, A. (2001) La modernidad desbordada. Dimensiones culturales de la globalización. Montevideo: Ediciones Tricel.

Babadzan, A. (2009) Le spectacle de la culture. Globalisation et traditionalisme en Océanie. Paris: L'Harmattan.

Baessler, A. (1900) Neue Südsee-Bilder. Berlin: Verlag Von George Reiner.

Barth, F. (1976) Los grupos étnicos y sus fronteras: la organización social de las diferencias culturales. México DF: Fondo de Cultura Económica.

Biblioteca Nacional del Congreso de Chile (BNC) (2013) Reporte Estadísticas Comunales 2013. Isla de Pascua. Disponible en: http://reportescomunales.bcn.cl/2013/index.php/Isla_de_Pascua Fecha de consulta: 20 de mayo 2014.

Cristino, C.; Recasens, A.; Vargas, P.; Gonzaléz, L.; \& Edward, E. (1984) Isla de Pascua: Procesos, alcances y efectos de la aculturación. Santiago: Facultad de Arquitectura y Urbanismo e Instituto de Estudios Isla de Pascua. Universidad de Chile.

Cristino, C. \& Fuentes M. (comp). (2011) La compañía explotadora de Isla de Pascua. Patrimonio, memoria e identidad en Rapa Nui. Concepción: Ediciones Escaparate.

Delsing, R. (2009) Articulating Rapa Nui: Polynesian Cultural Politics in a Latin American Nation State. Tesis de Doctorado. Universidad de California, Santa Cruz.

Departamento de Historia Militar (2006) "El Ejército y el Pueblo Rapanui”. Cuaderno de Historia Militar, №2, pp. 47-114. Santiago: Instituto Geográfico Militar.

Di Castri, F. (1999) "Scenarios of tourism development in Easter
Island". Insula, International Journal of Island Affairs. Vol. 8(3), pp 3-15.

Empresa Nacional de Abastecimiento de Zonas Aisladas (EMAZA). (2009) Memoria anual. Ministerio de Economía, Gobierno de Chile.

Englert, S. (1960) "Aventuras marinas de nativos de Rapa Nui". Revista de Marina. Vol.76, pp. 465-475.

Eriksen, T. (1993) Ethnicity and nationalism. Anthropological perspectives. Londres: Pluto Press.

Escobar, B. \& Lagos, X. (2009) Voces del Pacífico. Una comunidad en búsqueda del reconocimiento autonómico. Tesis para optar al título profesional y grado de Antropólogo social. Santiago: Universidad Academia de Humanismo Cristiano.

Fages, J. (1973) "Les migrations humaines en Polynésie française". Cahier OSTROM, Série Sciences Humaines, Vol X, №2(3), pp.289-293 (1974) "Migrations et urbanisation en Polynésie française". Cahier OSTROM, Série Sciences Humaines. Vol XI, $\mathrm{N}^{\circ} 3(4)$, pp.243-258.

Foerster, R. Ramírez, J. \& Zurob, C. (2012) "Un acercamiento a la historia reciente de Rapa Nui: bases contextuales para una interpretación del presente". Apuntes del Museo $N^{\circ} 1$. Rapa Nui, Chile: Biblioteca William Mulloy, pp. 36- 52.

Foerster, R. \& Montecino, S. (2013) "Rapa Nui: la lepra y sus derivados (estado de excepción, cárcel...)". Disponible en: http://www.escriturasamericanas. cl/revista/revista01/02_03_rapa_nui.pdf Fecha de consultā: 25 de mayo 2014

Fuentes, M. (comp). (2013) Rapa Nui y la Compañía Explotadora. 1895-1953. Rapa Nui, Chile: Rapa Nui Press.

Grifferos, A. (1995) La otra cara del paraíso. Comunidad, tradición y colonialismo en Rapanui 1864-1964. Tesis para optar al grado de licenciada en historia. Facultad de Derecho y Ciencias Sociales. Valparaíso: Universidad de Valparaíso.

Godelier, M. (1984) L'idéel et le matériel. Pensée, économies, sociétés. Francia: Librairie Arthème Fayard. (1998) El enigma del don. Madrid: Paidos.

Goñi, A. (1983) "El migrante pascuense en el continente: 1968-1971". Arqueología y Ciencia, Primeras jornadas. Santiago: Museo Nacional de Historia Natural, pp. 218-258.

Hau'ofa, E. (1993) "Our sea of islands." En: Waddell, E. Naidu \& E. Hau'ofa, E. A new Oceania: Rediscovering our Sea of Islands. Suva, Fij: USP, pp. 3-16.

Instituto Nacional de Estadísticas (INE). (1993) Censo de población y vivienda 1993. Base de datos accesible en línea: www.ine.cl Fecha de consulta: 25 de mayo 2014

(2002) Censo de población y vivienda 2002. Base de datos disponible en: http://espino.ine.cl/cgibin/ RpWebEngine.exe/PortalAction? \&BASE=CPCHL2KREG Fecha de consulta: 25 de mayo 2014

Institute de la Statistique de la Polynésie française (ISPF). (2002) Recensement Général de la Population du 7 novembre 2002. ISPF, Tahiti. 
(2007) Recensement Général de la Population de la Polynésie française 2007. ISPF, Tahiti.

(2013) Recensement de la Population du 22 aout au

18 septembre. ISPF, Tahiti.

Levi-Strauss, C. (1949) Les Structures élémentaires de la parenté. Paris: PUF.

Marcus, G. (2001) "Etnografía en/del sistema mundo. El surgimiento de la etnografía multilocal”. Revista Alteridades №22, p.111-127.

Montecino, S. (2010) Fuegos, Hornos y donaciones. Alimentación y cultura en Rapa Nui. Santiago: Editorial Catalonia.

Moreno Pakarati, C. (2012) "¿Soldados rapanui en la guerra del Pacífico? Un estudio preliminar”. Apuntes del Museo №1. Rapa Nui: Biblioteca William Mulloy, pp. 11-23.

Muñoz, D. (2007) Rapanui Translocales. Configuracion de la identidad rapanui en Santiago de Chile. Tesis para optar al grado de licenciado en antropología social y título profesional de antropólogo. Santiago: Universidad Academia de Humanismo Cristiano.

(2010) Au-delà de l'île de Pâques. De l'insularité et des flux dans l'identité rapanui contemporaine. Memoria de Master en Etnología y Antropología Social. Paris: EHESS.

(2014a) "Kinship Predicaments in Rapa Nui

(Easter Island): Autochthony, Foreign and Substantial Identities". Rapa Nui Journal Vol. 28 (2), pp. 25-34.

(2014b) "Las tierras rapanui de Pamatai (Tahiti). Estudio genealógico y de propiedad”. Apuntes del Museo №3. Rapa Nui: Biblioteca William Mulloy. pp. 31-74.

McCall, G. (1975) "Shorter communications: Sympathy and antipathy in Easter Islander and Chilean relations". The Journal of the Polynesian Society. Vol. 84, pp. 467-476.

(1976) Reaction to disaster: Continuity and change in Rapanui Social organization. Tesis de Doctorado. Australian National University.

(1980) "Kinship and association in Rapanui reciprocity".

Pacific Studies. Vol. 3(2), pp. 1-21.

(1996) "El pasado en el presente de Rapanui (Isla de

Pascua)". Hidalgo, J. Shiappacasse, V., Niemeyer, H., Aldunate, C. \& Mege, P. (comp.) Etnografía. Sociedades indígenas contemporáneas y su ideología. Santiago: Editorial Andrés Bello, pp. 17-46.

(1997) "Rapanui wanderings: Diasporas from Easter

Island". En: Stevenson, C. Lee,G. \& Morin, J-F. Easter Island in Pacific Context South Seas Symposium. Los Osos: Easter Island Foundation, pp. 370-378.

(1998) Rapa Nui: Tradición y sobrevivencia en Isla de Pascua. Los Osos: Easter Island Foudation.

Peteuil, M-F. (2004) Les évadés de L'île de Pâques. Loin du Chili, vers Tahiti (1944-1958). Paris: L'Harmattan

Porteous, D. (1981) The modernization of Easter Island. Western Geographical Series Volume 19. Canada: University of Victoria.
Ramírez, M.F. (2010) El cambio alimentario en Rapa Nui. Usos, desusos y significados asociados a los alimentos en sus procesos de producción, distribución, preparación y consumo. Tesis para optar al grado de Licenciado en Antropología Social y título profesional de Antropólogo. Santiago: Universidad Academia de Humanismo Cristiano.

Rallu, J.L. (1994) "Tendances récentes des migrations dans le Pacifique Sud". Espaces, populations, sociétés. №2, pp. 201-212.

Saura, B. (2008) Tahiti Ma'ohi. Culture, identité, religion et nationalisme en Polynésie Française. Pirae Tahiti: Au Vent des lles.

Sahlins, M. (1997) "O 'pessīmismo sentimental' e a experiência etnográfica: por que a cultura não é um ‘objeto’ em via de extinção”. Revista Mana. №3 (1)-(2), pp. 41-73; pp. 103-150.

(2007) La découverte du vrai Sauvage et autres essais. Lonrai, Francia: Gallimard.

Seelenfreund, A. (Ed). (2013) Vistiendo Rapa Nui. Textiles vegetales. Haka'ara o te Kahu. Santiago: Editorial Pehuen.

Seelenfreund, A., Grifferos, A., Hucke, P. \& Ramirez J.M. (2004) "Los Rapanui de Te Pito O Te Henua", en Bengoa, J. (comp). La Memoria olvidada. Historia de los Pueblos Indígenas de Chile. Santiago: Publicaciones del Bicentenario, pp.607-664.

Servicio Nacional de Turismo (SERNATUR). (2004) Anuario de turismo 2003. Instituto Nacional de Estadísticas y Servicio Nacional de Turismo. Gobierno de Chile.

(2012) Anuario de turismo 2011. Instituto Nacional de

Estadísticas y Servicio Nacional de Turismo. Gobierno de Chile. (2013) Anuario de turismo 2012. Instituto Nacional de

Estadísticas y Servicio Nacional de Turismo. Gobierno de Chile.

Tcherkézoff, S. (1999) Le mythe occidental de la sexualité polynésienne. Paris: PUF.

Torres, F. (2012) "Situación del arte y la artesanía rapanui". Consejo Nacional de las Artes y la Cultura. Estudio diagnóstico del desarrollo cultural del pueblo rapanui, pp.235-260. Disponible en: http://www.cultura.gob.cl/estudios/observatorio-cultural/ estudiodiagnósticodeldesarrolloculturaldelpueblorapanui.htm Fecha de consulta: 20 de agosto 2013.

Toullelan, P \& Gille, B. (1999) De la conquête à l'exode. Histoire des Océaniens et leurs migrations dans le Pacifique. Tome 2. Papeete, Tahiti: Au Vent des lles.

Weisner, M \& Fajreldin, V. (2003) "Mi remedio pascuense. Cultura Medico-Política en Rapanui”. Revista de la Escuela de Antropología. Universidad Nacional de Rosario,VIII. pp. 43-58.

Zurob, C. (2010) Ta'aku Poki: cambio y continuidad en las estrategias de crianza rapanui. Un acercamiendo a la transición en diferencia. Memoria parā optar al título profesional de Antropólogo Social. Universidad de Chile. 